\title{
Dynamic impact response of high-density square honeycombs made of TRIP steel and TRIP matrix composite material
}

\author{
D. Ehinger ${ }^{1}$, L. Krüger ${ }^{1}$, S. Krause ${ }^{1}$, U. Martin ${ }^{2}$, C. Weigelt ${ }^{3}$, and C.G. Aneziris ${ }^{3}$ \\ ${ }^{1}$ Institute of Materials Engineering, Technische Universität Bergakademie Freiberg, 09599 Freiberg, Germany \\ ${ }^{2}$ Institute of Materials Science, Technische Universität Bergakademie Freiberg, 09599 Freiberg, Germany \\ ${ }^{3}$ Institute of Ceramic, Glass and Construction Materials, Technische Universität Bergakademie Freiberg, 09599 \\ Freiberg, Germany
}

\begin{abstract}
Two designs of square-celled metallic honeycomb structures fabricated by a modified extrusion technology based on a powder feedstock were investigated. The strength and ductility of these cellular materials are achieved by an austenitic CrNi (AISI 304) steel matrix particle reinforced by an $\mathrm{MgO}$ partially-stabilized zirconia building up their cell wall microstructure. Similar to the mechanical behaviour of the bulk materials, the strengthening mechanism and the martensitic phase transformations in the cell walls are affected by the deformation temperature and the nominal strain rate. The microstructure evolution during quasi-static and dynamic impact compression up to high strain rates of $10^{3} 1 / \mathrm{s}$ influences the buckling and failure behaviour of the honeycomb structures. In contrast to bending-dominated quasi-isotropic networks like open-celled metal foams, axial compressive loading to the honeycomb's channels causes membrane stretching as well as crushing of the vertical cell node elements and cell walls. The presented honeycomb materials differ geometrically in their cell wall thickness-to-cell size-ratio. Therefore, the failure behaviour is predominantly controlled by global buckling and torsional-flexural buckling, respectively, accompanied by plastic matrix flow and strengthening of the cell wall microstructure.
\end{abstract}

\section{Introduction}

The development and synthesis of low-density cellular structures building up of a bionic network of solid and space have been of great importance in recent decades [1-3]. Especially foams and honeycomb materials are widely used in cushioning, packaging and energyabsorption applications. Because of their two-dimensional, periodic cell array, the common honeycomb structures exhibit an anisotropic deformation behaviour depending on loading direction. Under compressive in-plane loading (viz. parallel to the cell lattice) thin-walled honeycomb materials with hexagonal or square cells behave like isotropic open-celled foams operating as a bendingdominated mechanism [3,4]. However, the highest potential for structural applications is obtained in the outof-plane crushing mode where the honeycomb's cell node elements and cell walls are subjected to axial membrane stresses. This stretching-dominated buckling and collapse behaviour is used for sandwich panels, which benefit from the high elastic stiffness and strength-to-weight ratio of their honeycomb core material [3]. Generally, metallic honeycomb cores in sandwich components have a low slenderness ratio and a maximum relative density $\left(\rho^{*} / \rho_{s}\right)$ (viz. the ratio of global density of the cellular structure to the density of the solid bulk material) of 0.05 [3]. Wang and McDowell found out that plastic yielding near the cell nodes in square-celled honeycombs is performed if $\left(\sigma_{\mathrm{ys}} / \mathrm{E}_{\mathrm{s}}\right) \approx 10^{-3}$ and $\left(\rho^{*} / \rho_{\mathrm{s}}\right) \geq 0.0698$ [3]. High-density honeycomb structures which deform by plastic buckling and progressive folding or shear are rather of interest for crash situations in civil and military transport to withstand high impact loads and ballistic collisions, respectively (cf. [5]).

In this study, the rate-dependent compressive stressstrain behaviour of two square-celled honeycomb structures made of an austenitic CrNi steel and a TRIP steel matrix composite was investigated. Both the zirconia particle reinforcement and the TRIP effect due to the deformation-induced martensitic phase transformation in the steel matrix significantly influence the evolution of the cell wall microstructure. The mechanical response and energy consumption as well as the buckling and failure mechanisms of the honeycombs are discussed with respect to their material and structure design over a wide range of strain rate.

\section{Materials and methods}

The square-celled honeycomb structures were fabricated by a powder metallurgical route of extrusion [6]. Before plastic moulding in a screw extruder, the raw powder feedstock based on an austenitic CrNi AISI 304 steel and different fractions of an MgO-partially stabilised zirconia (Mg-PSZ) ceramic was blended with certain bindering agents and deionised water. After the extrusion, debindering and sintering steps, two lattice structures with an average wall thickness of $\mathrm{t}=257 \pm 10 \mu \mathrm{m}$ but different cell size dimensions $\left(l_{1}=2310 \pm 15 \mu \mathrm{m}, l_{2}=1157 \pm 10 \mu \mathrm{m}\right.$, as seen in Figure 1) were created. In summary, two material compositions, namely the pure TRIP steel and the TRIPmatrix composite material with 5 vol. $\%$ zirconia were used for this study. At the beginning, similarly produced bulk materials were tested under quasi-static and dynamic compressive loading. Hence, the measured stress-strain responses of the honeycombs could be correlated to the bulk material behaviour. The chemical analyses of the steel matrices and the zirconia powder are given in Tables 1 and 2 .

In terms of the test series at different strain rates, cylindrical compact specimens with dimensions of 
Table 1. Chemical compositions (in wt\%) of the TRIP steel matrices in the compact bulk and honeycomb materials.

\begin{tabular}{|l|c|c|c|c|c|c|}
\hline & $\mathrm{C}$ & $\mathrm{Cr}$ & $\begin{array}{c}\mathrm{Ni} \\
\mathrm{i}\end{array}$ & $\mathrm{Mn}$ & $\mathrm{Si}$ & $\begin{array}{c}\text { Fe and } \\
\text { others }\end{array}$ \\
\hline \multicolumn{7}{|c|}{ a) compact bulk materials: } \\
\hline TRIP steel & 0.045 & 19.43 & 11.06 & 1.47 & 0.52 & bal. \\
\hline $\begin{array}{l}\text { Composite } \\
5 \% \mathrm{ZrO}_{2}\end{array}$ & 0.044 & 18.71 & 10.47 & 1.38 & 0.50 & bal. \\
\hline \multicolumn{7}{|c|}{ b) honeycomb materials: } \\
\hline TRIP steel & 0.042 & 18.60 & 9.25 & 0.92 & 0.53 & bal. \\
\hline $\begin{array}{l}\text { Composite } \\
5 \% \mathrm{ZrO}_{2}\end{array}$ & 0.060 & 17.80 & 9.07 & 1.03 & 0.56 & bal. \\
\hline
\end{tabular}

Table 2. Chemical analysis (in wt\%) of the Mg-PSZ powder.

\begin{tabular}{|l|c|c|c|c|c|}
\hline $\mathrm{MgO}$ & $\mathrm{SiO}_{2}$ & $\mathrm{HfO}_{2}$ & $\mathrm{Al}_{2} \mathrm{O}_{3}$ & $\mathrm{TiO}_{2}$ & $\mathrm{ZrO}_{2}$ \\
\hline 3.4 & 2.4 & 1.7 & 0.6 & 0.1 & bal. \\
\hline
\end{tabular}

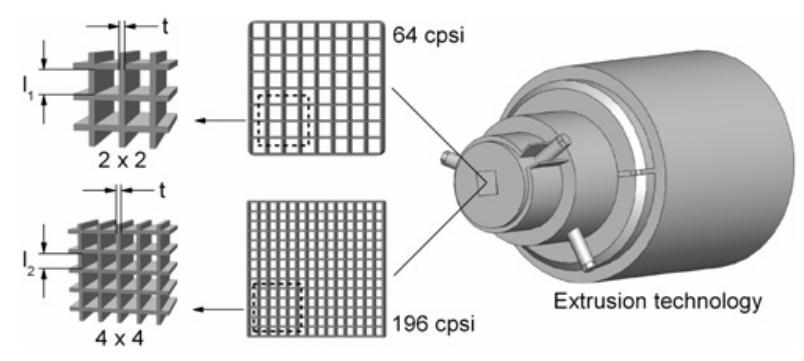

Fig. 1. Honeycomb designs after processing and preparation.

$6 \mathrm{~mm} \times 6 \mathrm{~mm}$ and honeycomb specimens with outer square dimensions of $8 \mathrm{~mm} \times 8 \mathrm{~mm}$ were prepared. The quasistatic and moderate compression tests between $10^{-3}$ and $10^{-1} 1 / \mathrm{s}$ were performed in a servohydraulic universal testing machine. For the dynamic impact and high rate experiments a drop weight tower and a Split-HopkinsonPressure-Bar (SHPB) were applied. Due to the limited diameter of the SHPB pressure bars $\left(d_{b}=19.8 \mathrm{~mm}\right)$, the honeycomb samples had to be cut out from the larger sintered products, as already mentioned above. In dependence on the cellular design, the final honeycomb specimens had an in-plane array of $2 \times 2$ (64 cpsi) or $4 \times 4$ (196 cpsi) closed cells (Figure 1). Including the residual micro-porosity after processing, their relative density values were about 0.23 and 0.37 , respectively.

The dynamic impact test setups were equipped by impact plates as well as stopping rings in order to investigate the buckling and failure mechanism of the honeycomb samples at certain deformation stages.

\section{Results and discussion}

\subsection{Behaviour of the bulk material}

The compressive flow curves of the bulk materials (Figure 2) demonstrate the effects of strain rate and particle reinforcement. As expected, the compressive yield stress rises with zirconia addition and increasing strain

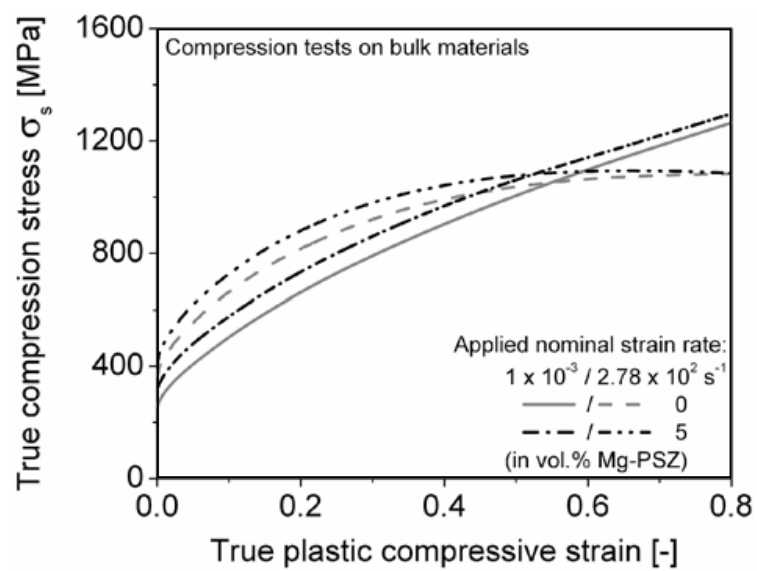

Fig. 2. Flow curves of the bulk materials under compressive loading at strain rates of $1 \times 10^{-3}$ and $2.78 \times 10^{2} 1 / \mathrm{s}$.

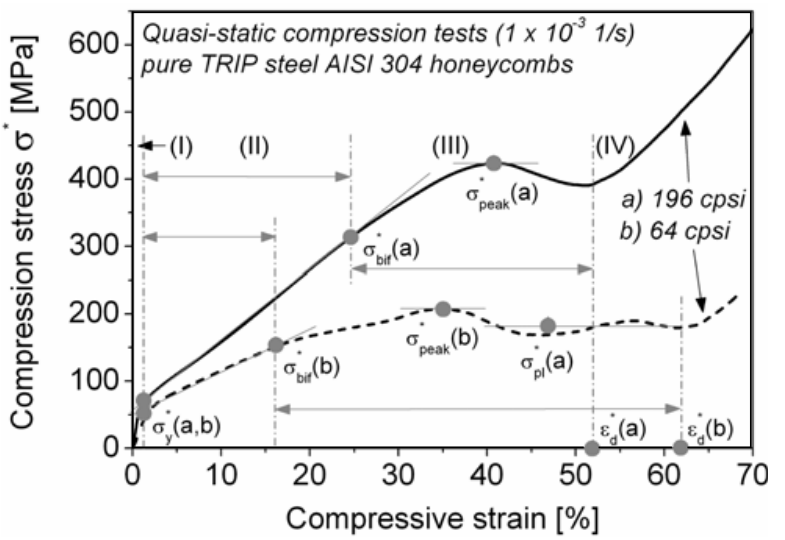

Fig. 3. Stress-strain responses and deformation stages for two different honeycomb structures (196 cpsi and $64 \mathrm{cpsi}$ ).

rate. Under dynamic impact loading (strain rate of $2.78 \times$ $10^{2} 1 / \mathrm{s}$ ), the stress-strain behaviour of the bulk materials is superimposed by a quasi-adiabatic heating effect which is responsible for an increase of the stacking fault energy and the reduction of the formation rate of $\alpha^{\prime}$-martensite in the steel matrix, respectively (cf. [7-9]). Hence, the TRIP steel and TRIP steel matrix composite show a material softening at higher deformation degrees and high strain rates.

\subsection{Stress-strain response of the honeycombs}

Figure 3 shows representative stress-strain curves of the two honeycomb structures, considering the different deformation and buckling stages. In this case, pure TRIP steel cubic specimens with the initial as-sintered geometries of $8 \times 8$ (viz. 64 cpsi) and $14 \times 14$ cells (viz. $196 \mathrm{cpsi}$ ) were deformed under quasi-static compressive loading in outof-plane direction.

Following the buckling regime of plates or tubes, the structural response of the honeycomb structures can be classified in four stages, including a linear-elastic range (I), an inelastic pre-buckling (II) and post-buckling range (III) and a section of structure densification (IV). Characteristic points which denote the inelastic structural behaviour of the present honeycomb materials are the plastic yield stress 


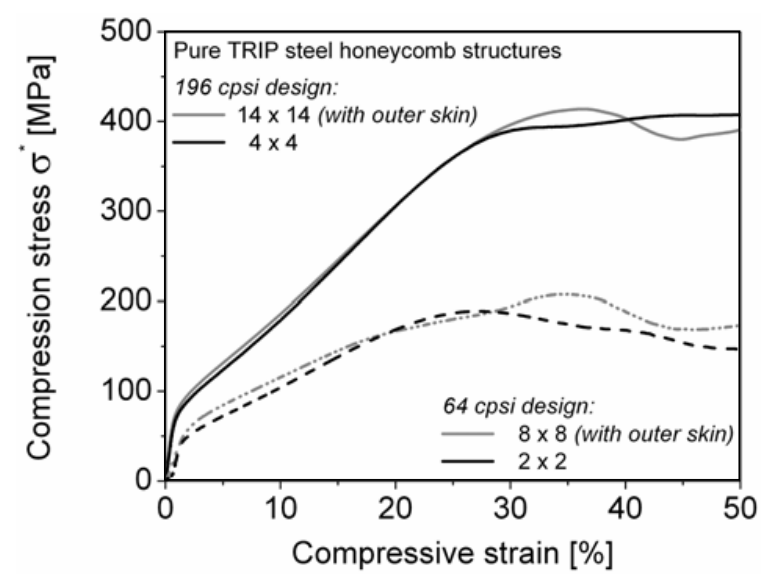

Fig. 4. Compressive stress-strain curves depending on cell size and cell number (quasi-static strain rate of $1 \times 10^{-3} 1 / \mathrm{s}$ ).

$\sigma_{\mathrm{y}}^{*}$, the plastic bifurcation stress $\sigma_{\mathrm{bif}}^{*}$, the compressive peak stress $\sigma_{\text {peak }}^{*}$, the plateau strength $\sigma_{\text {pl }}^{*}$ and the locking strain $\varepsilon_{\text {bif }}^{*}$ (as indicated in Figure 4). These parameters are dependent on the cell wall thickness-to-cell size-ratio and the relative density of the cellular material, respectively, and are mostly affected by the applied strain rate under compressive loading. By a comparison of the stress-strain responses of the larger honeycomb specimens (viz. $8 \times 8$ and $14 \times 14$ cells) with those of the down-scaled samples (viz. $2 \times 2$ and $4 \times 4$ cells), it can be noticed that the number of cells should not significantly influence the structural behaviour (Figure 4).

Only the stiffness factor of the outer skin around the asreceived sintered samples seems to affect slightly the strain hardening and the beginning of bifurcation or the position of the peak stress. Thereby, the presented investigations on the small honeycomb specimens can be compared with the results of previous studies $[6,7]$.

\subsection{Dynamic behaviour of the honeycombs}

In order to apply the classical elastic one-wave theory on the honeycomb compression tests in the SHPB apparatus, one fundamental assumption is that the cellular specimen should remain in equilibrium during high rate deformation [10]. Cady et al. [2] found out that aluminium foams can no longer achieve a stress-state-equilibrium at a strain rate above $20001 / \mathrm{s}$ because of the formation of inhomogeneous crushing zones. In this study, the equilibrium state was verified by comparing the 1 -wave and 2 -wave stress vs. time and strain rate vs. time histories, measured for two material conditions with different cell designs. To determine the time histories of stress and strain rate within the specimen the following equations based on one-wave and two-wave analyses were applied:

a) 1-wave theory:

$$
\begin{gathered}
\sigma_{h_{1}}(t)=E_{b} \cdot \frac{A_{b}}{A_{h}} \cdot \varepsilon_{t}(t)=\text { on rear face } \\
\dot{\varepsilon}_{h_{1}}(t)=-\frac{2 \cdot c_{b}}{l_{h}} \cdot \varepsilon_{r}(t)
\end{gathered}
$$

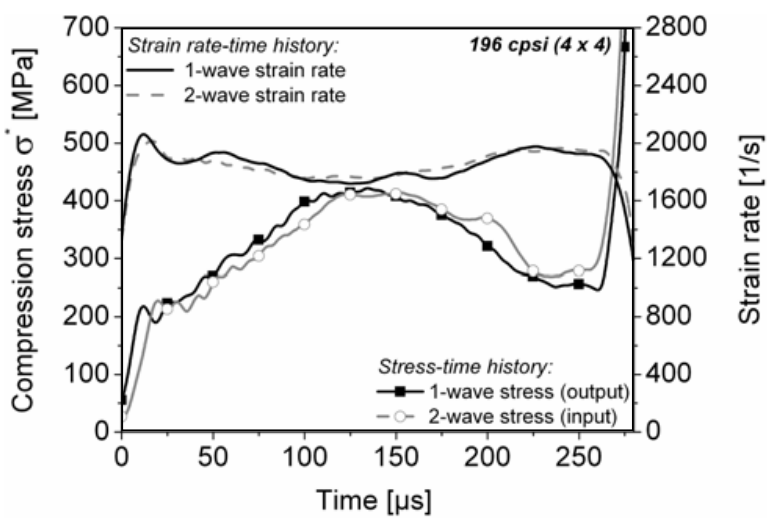

Fig. 5. Stresses and strain rates vs. time for a $4 \times 4$-celled honeycomb composite specimen comparing 1-wave and 2-wave analysis at an applied test strain rate of $1.9 \times 1031 / \mathrm{s}$.

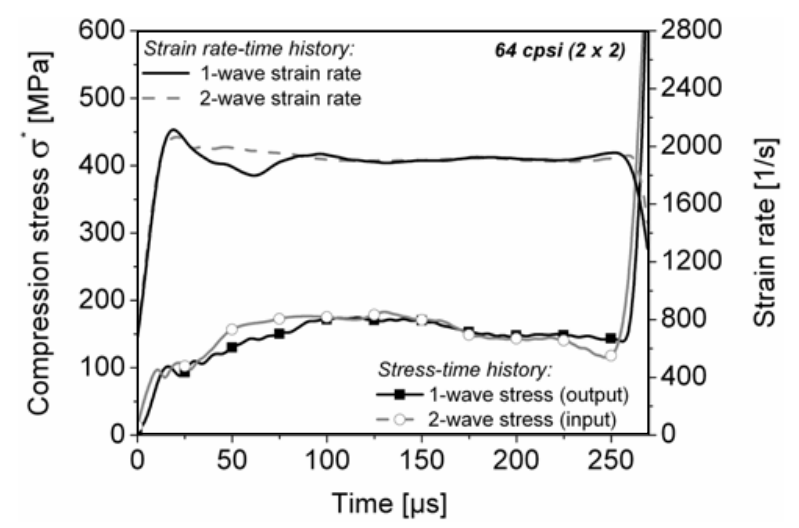

Fig. 6. Stresses and strain rates vs. time for a $2 \times 2$-celled honeycomb steel specimen comparing 1 -wave and 2 -wave analyses at an applied test strain rate of $1.9 \times 10^{3} 1 / \mathrm{s}$.

b) 2-wave theory:

$$
\begin{gathered}
\sigma_{h_{2}}(t)=E_{b} \cdot \frac{A_{b}}{A_{h}} \cdot\left(\varepsilon_{i}(t)+\varepsilon_{r}(t)\right)=\text { on front face } \\
\dot{\varepsilon}_{h_{2}}(t)=-\frac{2 \cdot c_{b}}{l_{h}} \cdot\left(\varepsilon_{t}(t)-\varepsilon_{i}(t)\right)
\end{gathered}
$$

for the assumption that $\varepsilon_{r}(t)=\varepsilon_{t}(t)-\varepsilon_{i}(t)$ [10].

The bar material (maraging steel X3NiCoMoTi8-9-5) is characterised by the following parameters: the elastic modulus $E_{b}=191606 \mathrm{MPa}$, the cross-sectional area $A_{b}=$ $(\pi / 4)\left(d_{b}\right)^{2}$ and the longitudinal elastic wave speed $c_{b}=$ $4881 \mathrm{l} / \mathrm{s}$. Commonly, the strain signals of the incident, transmitted and reflected wave are given by $\varepsilon_{i}(t), \varepsilon_{t}(t)$ and $\varepsilon_{r}(t)$. Parameters, indexed by $h$, describe the properties of the honeycomb specimen with a cross-sectional area $A_{h}$ and a length $l_{h}$.

According to the calculations, the time histories of the measured stresses and strain rates in two honeycomb structures with different material compositions are displayed in Figures 5 and 6. For a better comparison, the raw strain signals were firstly adapted by a smoothing filter and normalised to the same time base.

As seen in the diagrams (Figures 5 and 6), the 2-wave stresses and strain rates oscillate around the determined 


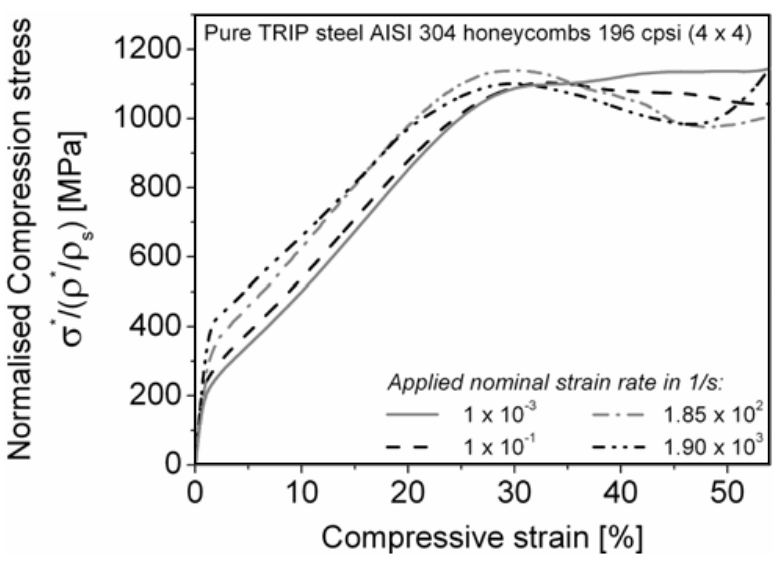

Fig. 7. Compressive stress-strain curves of the pure TRIP steel $4 \times 4$-celled honeycombs as a function of strain rate.

1-wave signals, indicating a stress-state equilibrium. This result confirms the statement of Radford et al. [11], who measured equal front and back stresses in comparable honeycomb steel specimens for test velocities up to 50 $\mathrm{ms}^{-1}$. Only just at an impact velocity of $v_{0}>50 \mathrm{~ms}^{-1}$, they suggested that a one-dimensional plastic wave propagation is responsible for the dynamic strength enhancement of the studied honeycomb structures. Altogether, this constitutes proof that the mechanical behaviour of the TRIP steel matrix honeycombs under compressive loading in out-ofplane direction and at an applied strain rate of 19001/s (viz. velocity of the striker bar $v_{0}=15.5 \mathrm{~ms}^{-1}$ ) can be described by the elastic one-wave analysis.

Figure 7 shows the compressive stress-strain curves for the pure TRIP steel $4 \times 4$-celled honeycombs (196 cpsi) over a wide range of nominal strain rate. In Figure 7 and further diagrams, the measured compression stress was normalised to the relative density of each specimen in order to give a better comparison. Similar to the bulk material, the compressive yield stress of the honeycomb structure continuously rises with increasing strain rate. As predicted by [4], the honeycomb's yield stress scales nearly linear to the plastic yield stress of the bulk material. The strain hardening response changes from a weak sigmoidal shape under quasi-static loading to a parabolic behaviour with lower slope at high strain-rate testing. This is attributed to the intrinsic dislocation-controlled processes and the martensite kinetic in the cell wall matrix as well as to the quasi-adiabatic heating at high strain rates [7-9].

The local softening processes due to the enclosed thermal energy in the honeycomb structure are superimposed by a dynamic strengthening mechanism at high strain rates $>10^{2} 1 / \mathrm{s}$. The bifurcation and the following compressive peak stress which initiate the collapse and post-buckling behaviour of the honeycomb structure, respectively, reveal almost no strain-rate dependence. This is in contrast to the results determined by [7] for the as-received $14 \times 14$ celled honeycombs, where the peak stress at the moderate strain rate of $1 \times 10^{-1} 1 / \mathrm{s}$ was significantly reduced. The decrease in the compressive strength was explained by the dominated material softening mechanisms at this strain rate. Obviously, the extent of the quasi-adiabatic heating and softening processes seems to be enhanced with higher

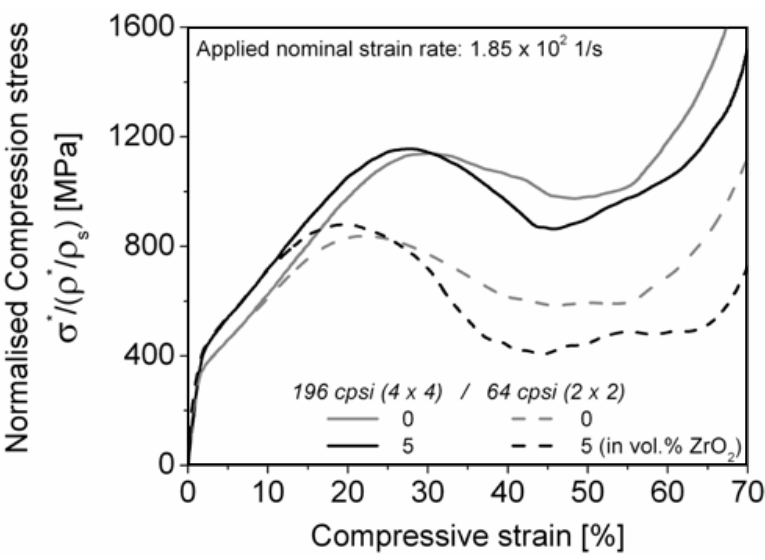

Fig. 8. Compressive stress-strain curves under dynamic impact loading $\left(1.85 \times 10^{2} 1 / \mathrm{s}\right)$ for the two honeycomb designs as a function of zirconia particle fraction.

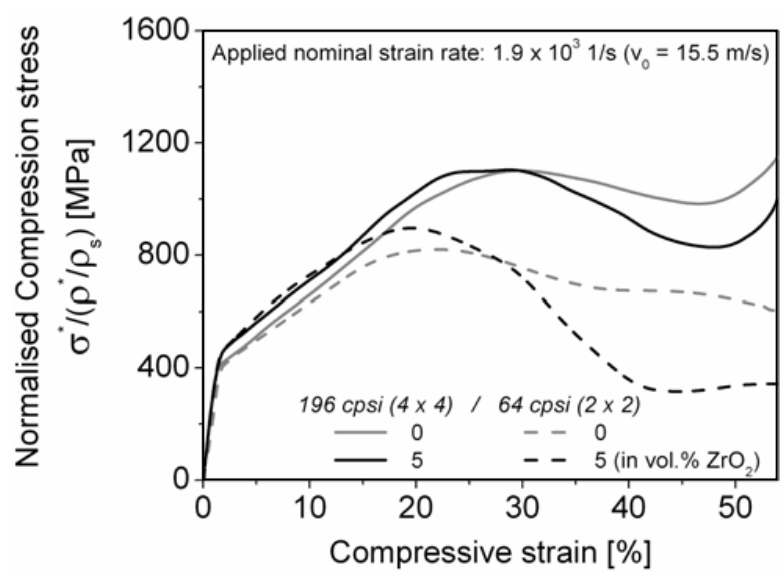

Fig. 9. Compressive stress-strain curves under high strain- rate loading in the SHPB apparatus $\left(1.9 \times 10^{3} 1 / \mathrm{s}\right)$ for the two honeycomb designs as a function of zirconia particle fraction.

material volume. After exceeding the maximum, the mean post-buckling stress changes with increasing strain rate. The pronounced collapse and damage evolution under high strain-rate compression is responsible for the gradual drop of the mean stress. As demonstrated in Figures 8 and 9, the particle reinforcement effect attributed to a zirconia particle fraction of $5 \mathrm{vol} . \%$ is most significant in the prebuckling stage of the $4 \times 4$-celled $(196 \mathrm{cpsi})$ and $2 \times 2$ celled (64 cpsi) honeycombs and has less influence on the compressive peak stress.

Since the stress in the pre-buckling range scales linear with relative density, the normalised compression stresses of the two different cellular designs are nearly congruent up to an engineering compressive strain of approximately 10\% (Figures 8 and 9). Due to crack formation and crack growth triggered by zirconia particles and particularly by ceramic clusters (cf. $[6,7,9]$ ), the structural damage is more pronounced in the composite specimens accompanied by a rough decrease in mean post-buckling stress and plateau strength at high strain rates, respectively.

By considering the whole test series, it can be noticed that the failure strain setting the compressive peak stress 

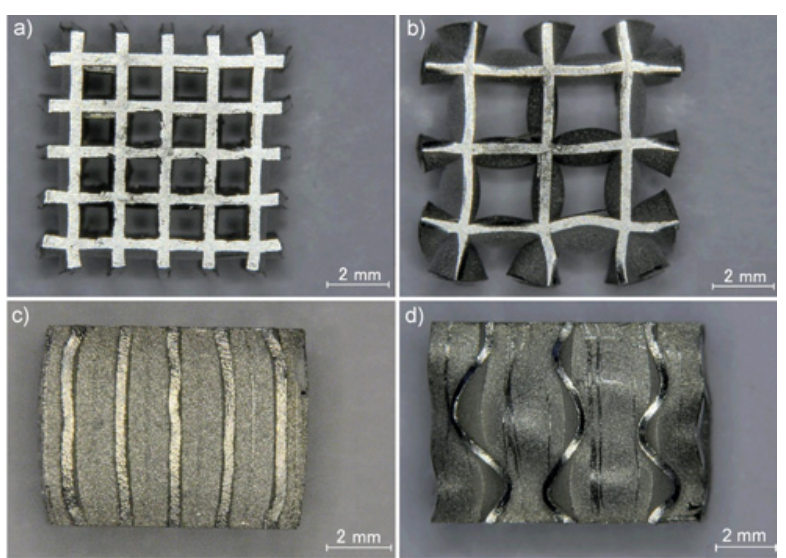

Fig. 10. Buckling patterns at $20 \%$ compressive strain under dynamic impact loading $\left(1.85 \times 10^{2} 1 / \mathrm{s}\right)$ : top and side view of a), c) $4 \times 4$-celled and b), d) $2 \times 2$-celled TRIP steel matrix honeycombs without macroscopically visible damage.

rises with increasing relative density (viz. from $64 \mathrm{cpsi}$ to $196 \mathrm{cpsi}$ honeycomb design), but decreases with the increase in volume content of zirconia particles and the increase in nominal strain rate. A significant strain rate dependence of the densification or locking strain was not proven. However, the beginning of structure densification is a function of the relative density of the honeycomb. In accordance to the investigations on stainless steel square honeycombs of Radford et al. [11], the compression stress enhancement attributed to dynamic loading at a test velocity $v_{0}<20 \mathrm{~ms}^{-1}$ (here $v_{0} \leq 15.5 \mathrm{~ms}^{-1}$ ) originates from the intrinsic strain rate sensitivity of the cell wall matrix material.

\subsection{Failure characteristics in the honeycombs}

In dependence on the cellular design or relative density (cf. Figures 10(a) and 10(b)), the TRIP steel matrix honeycomb structures exhibit a stretching-dominated deformation behaviour, which is initiated either by global inelastic "Euler" buckling or local inelastic torsional-flexural buckling of the cell walls. As displayed in Figure 10, the $4 \times 4$ celled honeycomb design with the higher relative density tends more to global buckling (Figure 10(c)) whereby the $2 \times 2$-celled lattice structure undergoes the second collapse mode (Figure 10(d)). While the high-density honeycomb still hardens at $20 \%$ compressive strain under dynamic impact loading, the low-density material has already exceeded its critical bifurcation limit, as indicated by large cell wall deflections.

In the post-buckling stage, the failure evolution continues by cell wall kink formation in the case of the $4 \times 4$-celled honeycomb or by progressive folding in the $2 \times 2$-celled lattice structure. The latter collapse mode is responsible for the longer stress plateau of the low-density honeycombs, as seen in Figure 8.

First macroscopic damage attributed to crack formation and fracture in cell wall crushed zones was observed after passing the compressive peak stress. The degree of damage is visibly higher for the composite materials at

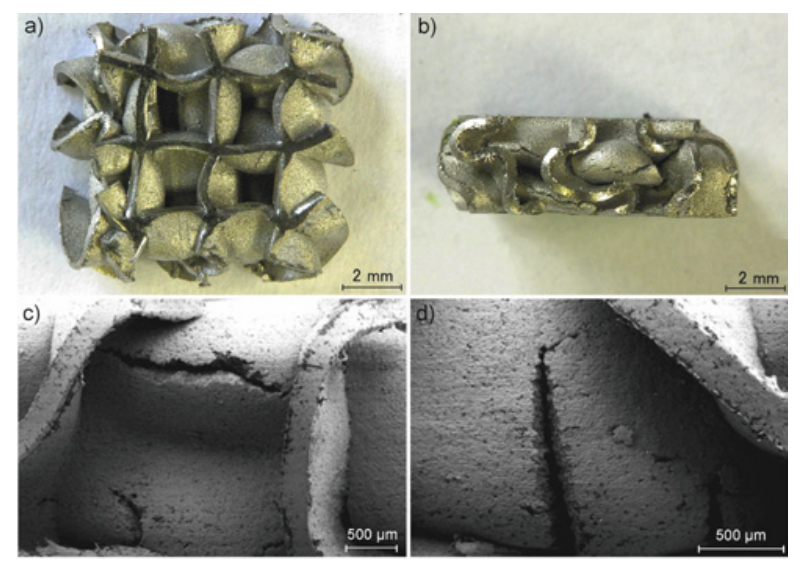

Fig. 11. Deformed $2 \times 2$-celled composite honeycomb at $50 \%$ strain under quasi-static loading $\left(1 \times 10^{-3} 1 / \mathrm{s}\right)$ : a), b) folding patterns; c), d) SE micrographs showing cracks in folds.

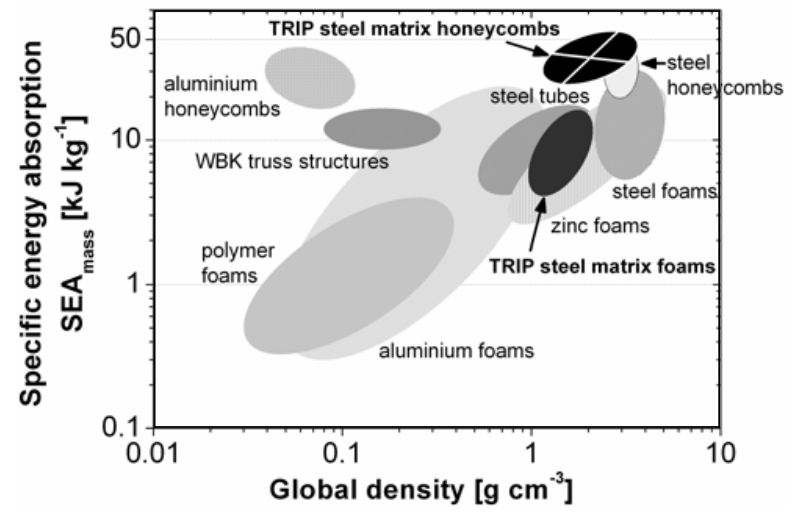

Fig. 12. Specific energy absorption per mass for the TRIP steel matrix honeycombs (196/64 cpsi) compared with other structures: foams made of aluminium [1], polymer [12], zinc composite [13], steel [14], TRIP steel matrix [15]; honeycombs based on aluminium [16], stainless steel [5,17]; Wire-woven Bulk Kagome (WBK) truss structures [18] and steel tubes [19].

high strain-rate testing; however, macro-cracks could be also recorded under quasi-static compression but mainly at higher strain levels.

Figure 11 presents the folding mechanism (Figures 11(a) and (b)) and crack formation in a $2 \times 2$-celled composite honeycomb at 50\% strain. Mostly, the damage is initiated on the surface of the cell wall folds attributed to high local tensile stresses (Figures 11(c) and (d)).

\subsection{Energy consumption in comparison}

Further investigations on the energy absorption capability of the TRIP steel matrix honeycomb structures give a first evaluation of their crashworthiness for automobile, railway or aircraft applications. The absorbed energy during plastic deformation was calculated by the integrated area under the force vs. displacement curves. Normalised to the mass of the specimen, a specific energy absorption value $S E A_{\text {mass }}$ (in $\mathrm{kJ} \mathrm{kg}^{-1}$ ) at $50 \%$ compressive strain could be determined. In order to compare the energy 
consumption of the TRIP steel matrix honeycombs with other cellular materials, all values displayed in Figure 12 were obtained under quasi-static compressive loading. Both the values of the tubes and honeycomb structures refer to compression in their stiffer out-of-plane channel direction.

As shown in Figure 12, the studied TRIP steel matrix honeycombs perform a maximum energy consumption of $54 \mathrm{~kJ} \mathrm{~kg}^{-1}$. Especially at lower deformation degrees, the specific energy absorption is affected by the stress enhancement due to the deformation-induced martensitic transformation in the steel matrix and the constraint effects of the zirconia particles. At high strain rate testing, a dynamic strengthening mechanism influences the prebuckling stage of the honeycombs and thus increases the energy absorption. However, the initial increase in absorbed energy at high strain rates is reduced with further deformation because of arising damage processes in the post-buckling stage.

\section{Conclusions}

The stress-strain response and the failure behaviour of two TRIP steel matrix square honeycomb structures were studied over a wide range of strain rate. Consistent with the bulk materials, the compressive yield stress and the strain hardening range are significantly affected by the particle reinforcement and strain-rate enhancement. As revealed by interrupted compression tests, the honeycomb specimens deform in different buckling and collapse modes depending on their relative density. Under dynamic impact loading in a SHPB apparatus, both honeycomb structures exhibit a uniaxial stress equilibrium. This fact constitutes the proof that the use of the elastic one-wave analysis for their stress-strain response is valid. Damage phenomena due to crack formation and cell wall fracture are more pronounced at high strain compression and in the composite honeycomb conditions, indicated by a significant stress drop in the post-buckling range. In comparison with other cellular structures, the TRIP steel matrix honeycombs show a high strength combined with high energy absorption.

\section{Acknowledgements}

The authors thank the German Science Foundation (DFG) for supporting this work in terms of the CRC 799.

\section{References}

1. A.G. Evans, J.W. Hutchinson, M. F. Ashby, Prog. Mater. Sci. 43 (1999)

2. C.M. Cady, G.T. Gray III, C. Liu, M.L. Lovato, T. Mukai, Mater. Sci. Eng. A 525 (2009)

3. A.-J. Wang, D.L. McDowell, Int. J. Plasticity, 21 (2005)

4. V.S. Deshpande, M.F. Ashby, N.A. Fleck, Acta Mater. $49(2001)$

5. W.E. Baker, T.C. Togami, J.C. Weydert, Int. J. Impact Eng. 21, 3 (1998)

6. L. Krüger, D. Ehinger, U. Martin, S. Martin, C. Weigelt, C.G. Aneziris, WIT Trans. Built Env. 112 (2010)

7. D. Ehinger, L. Krüger, U. Martin, C. Weigelt, C.G. Aneziris, steel research int. 82, 9 (2011)

8. L. Krüger, S. Wolf, S. Martin, U. Martin, A. Jahn, A. Weiß, P. Scheller, Steel Research Int. 82, 9 (2011)

9. L. Krüger, S. Decker, R. Ohser-Wiedemann, D. Ehinger, S. Martin, U. Martin, H. J. Seifert, Steel Research Int. 82, 9 (2011)

10. B.A. Gama, S.L. Lopatnikov, J.W. Gillespie Jr., Appl. Mech. Rev. 57, 4 (2004)

11. D.D. Radford, G.J. McShane, V.S. Deshpande, N.A. Fleck, ASME 74 (2007)

12. M.C. Saha, H. Mahfuz, U.K. Chakravarty, M. Uddin, E. Kabir, S. Jeelani, Mater. Sci. Eng. A 406 (2005)

13. A. Daoud, Mater. Sci. Eng. A 488 (2008)

14. C. Park, S.R. Nutt, Mater. Sci. Eng. A 299 (2001)

15. C.G. Aneziris, H. Berek, M. Hasterok, H. Biermann, S. Wolf, L. Krüger, Adv. Eng. Mater. 12, 3 (2010)

16. E. Wu, W.-S. Jiang, J. Impact Eng. 19, 5-6, (1997)

17. F. Coté, V.S. Deshpande, N.A. Fleck, A.G. Evans, Int. J. Solids Struct. 43 (2006)

18. B.-K. Lee, K.-J. Kang, Adv. Eng. Mater. 10, 9 (2008)

19. A.E. Ismail, Int. J. Eng. Tech. 5, 1 (2008) 